Article

\title{
Enantioseparation and Absolute Configuration Determination of Angular-Type Pyranocoumarins from Peucedani Radix Using Enzymatic Hydrolysis and Chiral HPLC-MS/MS Analysis
}

\author{
Yue-Lin Song ${ }^{1}$, Qing-Wen Zhang ${ }^{1}$, Ya-Ping $\mathrm{Li}^{1}{ }^{1}$, Ru Yan ${ }^{1, *}$ and Yi-Tao Wang ${ }^{1,2, *}$ \\ 1 State Key Laboratory of Quality Research in Chinese Medicine, Institute of Chinese Medical Sciences, \\ University of Macau, Taipa, Macao SAR, 999078, China \\ 2 School of Chinese Materia Medica, Beijing University of Chinese Medicine, Beijing 100029, China \\ * Authors to whom correspondence should be addressed; E-Mails: ruyan@umac.mo (R.Y.); \\ ytwang@umac.mo (Y.-T.W.); Tel.: +853-8397-4876 (R.Y.); Fax: +853-2884-1358 (R.Y.); \\ Tel.: +853-8397-4691 (Y.-T.W.); Fax: +853-2884-1358 (Y.-T.W.).
}

Received: 27 February 2012; in revised form: 29 March 2012 / Accepted: 31 March 2012 / Published: 10 April 2012

\begin{abstract}
Angular-type pyranocoumarins from Peucedani Radix (Chinese name: Qian-hu) have exhibited potential for use on treatment of cancer and pulmonary hypertension. Due to the existence of C-3' and C-4' chiral centers, compounds belonging to this chemical type commonly exist in enantiomers and/or diastereoisomers, which may elicit distinct activities during their interactions with the human body. In the present study, a new method, which combines enzymatic hydrolysis with chiral LC-MS/MS analysis, has been developed to determine the absolute configurations of these angular-type pyranocoumarins. Pyranocoumarins isolated from Qian-hu, their enantiomers, or metabolites were individually incubated with rat liver microsomes. As the common end product from enzymatic hydrolysis of all tested pyranocoumarins, cis-khellactone was collected and its absolute configuration was determined by comparison with $(+)$-cis-khellactone and (-)-cis-khellactone using chiral LC-MS/MS. The absolute configurations of all tested parent pyranocoumarins were determined by combination of LC-MS/MS, NMR and polarimetric analysis. The results revealed that the metabolite cis-khellactone retained the same absolute configurations of the stereogenic carbons as the respective parent compound. This method was proven to be rapid and sensitive and also has advantages in discriminating single enantiomers and mixtures of optical isomers with different ratios.
\end{abstract}


Keywords: angular-type pyranocoumarins; cis-khellactone; absolute configuration; enzymatic hydrolysis; chiral LC-MS/MS

\section{Introduction}

Peucedani Radix (Chinese name: Qian-hu) originates from the dried roots of Peucedanum praeruptorum DUNN, and has been used in traditional medicinal practice in China for the treatment of cough with thick sputum and dyspnea, nonproductive cough and upper respiratory infections $[1,2]$. Modern pharmacological studies have revealed potent hypotensive, coronary dilatory, myocardial protection and antitumor effects of this medicinal herb [2-5].

Angular-type pyranocoumarins, which comprise a khellactone (1, Figure 1) skeleton with C-3' and C-4' substituents, were reported as the main bioactive constituents of Qian-hu [6-9]. In the Chinese Pharmacopeia, praeruptorin A (cis-3'-angeloyl-4'-acetylkhellactone, 2) and praeruptorin B (cis-3', $4^{\prime}$ diangeloylkhellactone, 3) were documented as the chemical markers for quality control of this herb and related products [1]. Praeruptorin A and its analogues were revealed to be cytotoxic to some cancer cells [10-12] and were able to induce apoptosis as well as reverse multidrug resistance (MDR) [5] by suppressing expression of the efflux transporter P-glycoprotein [11]. Furthermore, the anticancer activity of praeruptorin $\mathrm{A}$ has also been demonstrated in mice [12], indicating the potential of these angular-type pyranocoumarins for cancer therapy. More interestingly, the two enantiomers of praeruptorin A (2a and $\mathbf{2 b}$, Figure 1) initiated distinct relaxant effects on isolated rat aorta rings dependent on endothelium and nitric oxide synthesis [13], indicating the existence of stereoselectivity in pharmacological activity of praeruptorin A.

Angular-type pyranocoumarins have two stereogenic centers (C-3' and C-4'). Enantiomers and diastereoisomers of this type of compounds naturally occur in some plants. In Qian-hu, the levorotatory isomers of praeruptorin A and praeruptorin B are naturally less abundant than their dextrorotatory enantiomers [6], indicating a chiral preference in the herb. In addition to praeruptorin A and praeruptorin $\mathrm{B}$, there are several other pyranocoumarin constituents naturally present as mixtures of enantiomers in the herb, but so far, only ( \pm )-praeruptorin A (2, Figure 1) has been enantioseparated by reversed-phase and normal-phase chiral chromatography $[13,14]$.

At present, the absolute configurations of this type of coumarin compounds are usually determined by acidic or alkaline hydrolysis in combination of gel column chromatographic separation $[6,7,15]$. However, the method using acid or base hydrolysis requires large amounts of pure compounds and the absolute configuration might be altered during acid or alkaline treatment [7,15]. Circular dichroism (CD) has also been adopted [13,16], but the CD spectrum couldn't distinguish the enantiomerically enriched compound from its pure enatiomer [17]. In contrast, enzyme-mediated hydrolysis generally breaks the ester bond without affecting the absolute configuration [18,19]. Our previous study on metabolism of $( \pm$ )-praeruptorin A by hepatic proteins from humans and rats also revealed that cis-khellactone obtained from the levorotatory enantiomer of praeruptorin A or its antipode retained the same absolute configuration as the parent enantiomer [14], indicating that the absolute configuration of pyranocoumarin constituents could be determined from their hydrolytic products 
formed from enzyme-mediated reactions. On the other hand, chiral LC-MS/MS analysis affords high selectivity and sensitivity to allow the determination of drugs and metabolites at low concentrations, thus, has been widely adopted in bioanalysis.

Figure 1. Chemical structures of pyranocoumarin compounds 1-11.

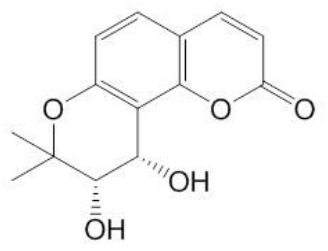

(1a)

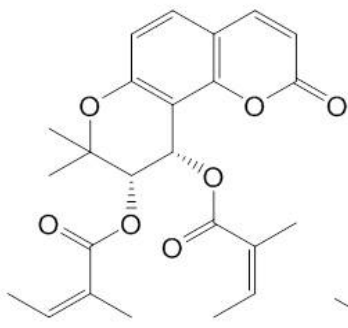

(3a)

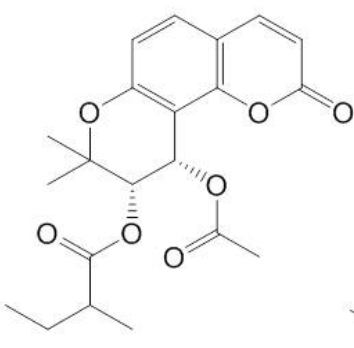

(6)

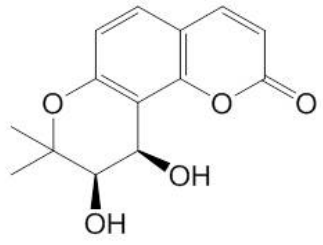

(1)

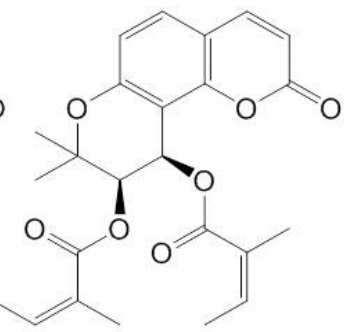

(3b)

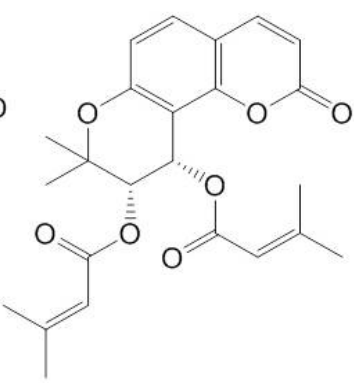

(7)

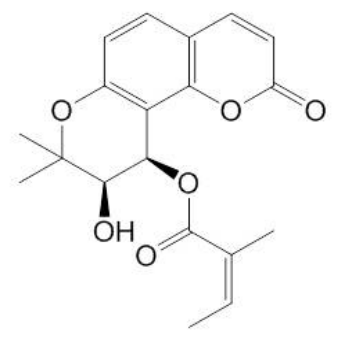

(10)

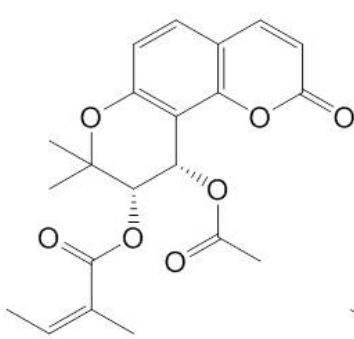

(2a)

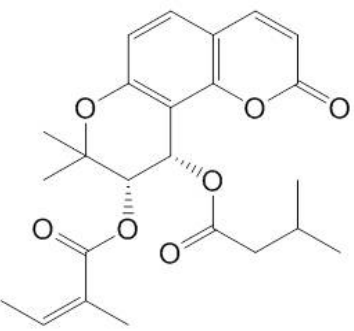

(4)

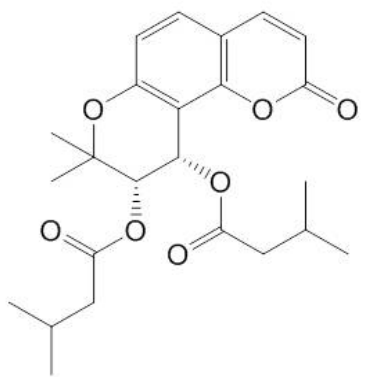

(8)

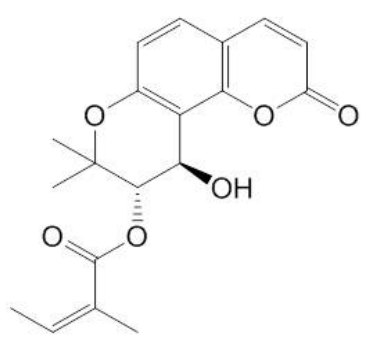

(11)

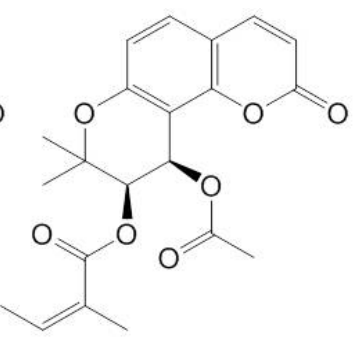

(2) $)$<smiles>C/C=C(/C)C(=O)O[C@H]1c2c(ccc3ccc(=O)oc23)OC(C)(C)[C@@H]1OC(C)=O</smiles>

(5)

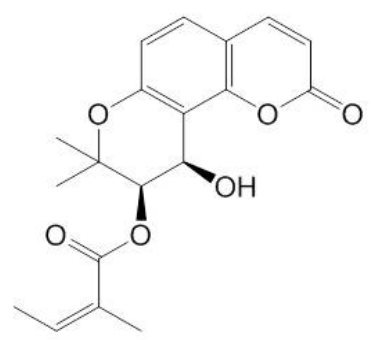

(9)

Therefore, in the present study, a method that combines enzymatic hydrolysis followed by chiral LC-MS/MS analysis of the metabolites formed was adopted for the first time to determine the absolute configurations of angular-type pyranocoumarin compounds from Qian-hu. The results obtained were consolidated with data from polarimetric analysis and NMR data or by comparison with the data of the reference compounds. 


\section{Results and Discussion}

\subsection{Identification of Pyranocoumarins from Qian-hu}

By comparing the NMR, MS data and optical rotations with the literature values (Tables 1 and 2), compounds 1-11 (Figure 1) were identified as $( \pm)$-cis-khellactone (1), ( \pm )-praeruptorin A [( \pm cis-3'angeloyl-4'-acetylkhellactone, 2], praeruptorin B [cis-3',4'-diangeloylkhellactone, 3], (+)-praeruptorin E [(+)-(3'S,4'S)-3'-angeloyl-4'-isovalerylkellactone, 4], cis-3'-acetyl-4'-angeloylkhellactone (5), cis-3'isovaleryl-4'-acetylkhellactone (6), (+)-cis-(3'S,4'S)-3'-angeloyl-4'-senecioylkhellactone (7), (+)-cis(3'S,4'S)-3', 4'-diisovalerylkhellactone (8), (-)-cis- $\left(3^{\prime} R, 4^{\prime} R\right)-3^{\prime}$-angeloylkhellactone (9), (-)-cis$\left(3^{\prime} R, 4^{\prime} R\right)-4^{\prime}$-angeloylkhellactone (10) and (+)-trans- $\left(3^{\prime} S, 4^{\prime} R\right)-3^{\prime}$-angeloylkhellactone (11), respectively.

\subsection{Enantioseparation of Mixtures of Angular-Type Pyranocoumarins}

Under the present analytical conditions, the enantiomers of $( \pm$ )-cis-khellactone (1) achieved good separation on a CHIRALPAK AD-RH semi-preparative column (Figure 2A). The two compounds were eluted at the retention times of $6.7 \mathrm{~min}(\mathbf{1 a})$ and $9.7 \mathrm{~min}(\mathbf{1 b})$, respectively. Their optical rotations were $[\alpha]_{\mathrm{D}}^{20}+57^{\circ}(c, 1.0)$ and $[\alpha]_{\mathrm{D}}^{20}-55^{\circ}(c, 1.0)$, which were in good agreement with those reported previously for $(+)$-cis-khellactone and $(-)$-cis-khellactone, respectively [20]. Thus, 1a was assigned as $(+)$-cis- $\left(3^{\prime} S, 4^{\prime} S\right)$-khellactone and $\mathbf{1 b}$ as $(-)$-cis- $\left(3^{\prime} R, 4^{\prime} R\right)$-khellactone (Figures 1 and $\left.2 \mathrm{~A}\right)$.

Enantioseparation of $\left( \pm\right.$ )-praeruptorin $\mathrm{B}\left(c i s-3^{\prime}, 4^{\prime}\right.$-diangeloylkhellactone, 3$)$ was achieved on the same chiral semi-preparative column using a mobile phase with a different acetonitrile $/ \mathrm{H}_{2} \mathrm{O}$ composition. The two enantiomers were eluted at $19.8 \mathrm{~min}(\mathbf{3 a})$ and $22.9 \mathrm{~min}(\mathbf{3 b})$, respectively. The optical rotations measured $\left[\mathbf{3 a},[\alpha]_{\mathrm{D}}^{20}+37^{\circ}(c, 1.0) ; \mathbf{3 b},[\alpha]_{\mathrm{D}}^{20}-36^{\circ}(c, 1.0)\right]$ for the enantiomers were similar to the data reported by Okuyama and co-workers [7]. Thus the two enantiomers were identified as (+)-praeruptorin B $\left[(+)\right.$-cis- $\left(3^{\prime} S, 4^{\prime} S\right)-3^{\prime}, 4^{\prime}$-diangeloylkhellactone, 3a] and (-)-praeruptoin B $\left[(-)\right.$-cis- $\left(3^{\prime} R, 4^{\prime} R\right)-3^{\prime}, 4^{\prime}$-diangeloylkhellactone, 3b] (Figures 1 and 2B).

\subsection{Determination of Absolute Configuration of Angular-Type Pyranocoumarins}

Our previous studies [14,21] and Ruan's report [22] on the metabolisms of ( \pm )-praeruptorin A (2), (+)-praeruptorin A (2a), (-)-praeruptorin A (2b), (+)-praeruptorin B (3a) and (+)-praeruptorin E (4) revealed that all these angular-type pyranocoumarins underwent stepwise hydrolysis and generated cis-khellactone without alteration of the absolute configuration when they were incubated with liver microsomal proteins from rats or humans in the presence of a NADPH-regenerating system. This finding suggests that the absolute configurations of this type of coumarins can be determined from the configurations of C-3' and C-4' of khellactone produced from hydrolysis of the parent coumarins by rat or human hepatic phase I isozymes. 
Table 1. HPLC-MS/MS data and optical rotations of pyranocoumarins from Qian-hu and their hydrolytic products.

\begin{tabular}{|c|c|c|c|c|c|c|}
\hline compound & $\mathbf{M S}^{1}$ & MW & $\mathbf{M S}^{2}$ & $\begin{array}{l}\text { Optical rotation (c } \\
\left.1.0, \mathrm{CDCl}_{3}\right)\end{array}$ & $\begin{array}{l}\text { Hydrolytic metabolite } \\
\text { (+/- cis-khellactone) }\end{array}$ & Identity \\
\hline 1 & $263[\mathrm{M}+\mathrm{H}]^{+} ; 285[\mathrm{M}+\mathrm{Na}]^{+}$ & 262 & 245,203 & $0^{\circ}$ & $+:-=1: 1$ & ( \pm )-cis-khellactone \\
\hline $1 \mathbf{a}$ & $263[\mathrm{M}+\mathrm{H}]^{+} ; 285[\mathrm{M}+\mathrm{Na}]^{+}$ & 262 & 245,203 & $-55^{\circ}$ & - & (-)-cis-(3'S, 4'S)-khellactone \\
\hline $1 \mathbf{b}$ & $263[\mathrm{M}+\mathrm{H}]^{+} ; 285[\mathrm{M}+\mathrm{Na}]^{+}$ & 262 & 245,203 & $+57^{\circ}$ & + & (+)-cis-(3'R, $\left.4^{\prime} R\right)$-khellactone \\
\hline 2 & $404\left[\mathrm{M}+\mathrm{NH}_{4}\right]^{+} ; 409[\mathrm{M}+\mathrm{Na}]^{+}$ & 386 & $327,245,227$ & $0^{\circ}$ & $+:-=1: 1$ & ( \pm )-cis-3'-angeloyl-4'-acetylkhellactone \\
\hline $2 \mathbf{a}$ & $404\left[\mathrm{M}+\mathrm{NH}_{4}\right]^{+} ; 409[\mathrm{M}+\mathrm{Na}]^{+}$ & 386 & $327,245,227$ & $+59^{\circ}$ & - & $(+)$-cis-(3'S, 4'S)-3'-angeloyl-4'-acetylkhellactone \\
\hline $\mathbf{2 b}$ & $404\left[\mathrm{M}+\mathrm{NH}_{4}\right]^{+} ; 409[\mathrm{M}+\mathrm{Na}]^{+}$ & 386 & $327,245,227$ & $-61^{\circ}$ & + & $(-)$-cis- $\left(3^{\prime} R, 4^{\prime} R\right)-3^{\prime}$-angeloyl-4'-acetylkhellactone \\
\hline 3 & $444\left[\mathrm{M}+\mathrm{NH}_{4}\right]^{+} ; 449[\mathrm{M}+\mathrm{Na}]^{+}$ & 426 & $327,245,227$ & $+3.4^{\circ}$ & $+:-=2: 3$ & $c i s-3^{\prime}, 4^{\prime}$-diangeloxylkhellactone \\
\hline $3 \mathbf{a}$ & $444\left[\mathrm{M}+\mathrm{NH}_{4}\right]^{+} ; 449[\mathrm{M}+\mathrm{Na}]^{+}$ & 426 & $327,245,227$ & $+36^{\circ}$ & - & (+)-cis-(3'S, 4'S)-3', 4'-diangeloxylkhellactone \\
\hline $\mathbf{3 b}$ & $444\left[\mathrm{M}+\mathrm{NH}_{4}\right]^{+} ; 449[\mathrm{M}+\mathrm{Na}]^{+}$ & 426 & $327,245,227$ & $-37^{\circ}$ & + & (-)-cis-( $\left(3^{\prime} R, 4^{\prime} R\right)-3^{\prime}, 4^{\prime}$-diangeloxylkhellactone \\
\hline 4 & $446\left[\mathrm{M}+\mathrm{NH}_{4}\right]^{+} ; 451[\mathrm{M}+\mathrm{Na}]^{+}$ & 428 & $327,245,227$ & $+35^{\circ}$ & - & (+)-cis-(3'S, $\left.4^{\prime} S\right)-3^{\prime}$-angeloxyl-4'-isovalerylkhellactone \\
\hline 5 & $404\left[\mathrm{M}+\mathrm{NH}_{4}\right]^{+} ; 409[\mathrm{M}+\mathrm{Na}]^{+}$ & 386 & $309,245,227$ & $+2.9^{\circ}$ & $+:-=7: 1$ & cis-3'-acetyl-4'-angeloylkhellactone \\
\hline $5 \mathbf{a}$ & $404\left[\mathrm{M}+\mathrm{NH}_{4}\right]^{+} ; 409[\mathrm{M}+\mathrm{Na}]^{+}$ & 386 & $309,245,227$ & $+3.5^{\circ}$ & + & $(+)$-cis- $\left(3^{\prime} R, 4^{\prime} R\right)-3^{\prime}$-acetyl-4'-angeloylkhellactone \\
\hline 6 & $406\left[\mathrm{M}+\mathrm{NH}_{4}\right]^{+} ; 411[\mathrm{M}+\mathrm{Na}]^{+}$ & 388 & $329,245,227$ & $+27^{\circ}$ & $+:-=1: 8$ & cis-3'-isovaleryl, $4^{\prime}$-acetylkhellactone \\
\hline $6 \mathbf{a}$ & $406\left[\mathrm{M}+\mathrm{NH}_{4}\right]^{+} ; 411[\mathrm{M}+\mathrm{Na}]^{+}$ & 388 & $329,245,227$ & $+33^{\circ}$ & - & (+)-cis-(3'S, 4'S)-3'-isovaleryl,4'-acetylkhellactone \\
\hline 7 & $444\left[\mathrm{M}+\mathrm{NH}_{4}\right]^{+} ; 449[\mathrm{M}+\mathrm{Na}]^{+}$ & 426 & $327,245,227$ & $+31^{\circ}$ & - & (+)-cis-(3'S, 4'S)-3'-angeloyl-4'-senecioylkhellactone \\
\hline 8 & $448\left[\mathrm{M}+\mathrm{NH}_{4}\right]^{+} ; 453[\mathrm{M}+\mathrm{Na}]^{+}$ & 430 & $329,245,227$ & $+35^{\circ}$ & - & $(+)-c i s-\left(3^{\prime} S, 4^{\prime} S\right)-3^{\prime}, 4^{\prime}$-diisovalerylkhellactone \\
\hline 9 & $367[\mathrm{M}+\mathrm{Na}]^{+} ; 383[\mathrm{M}+\mathrm{K}]^{+}$ & 344 & $267,245,227$ & $-57^{\circ}$ & + & $(-)$-cis- $\left(3^{\prime} R, 4^{\prime} R\right)-3^{\prime}$-angeloylkhellactone \\
\hline 10 & $367[\mathrm{M}+\mathrm{Na}]^{+} ; 383[\mathrm{M}+\mathrm{K}]^{+}$ & 344 & $267,245,227$ & $-39^{\circ}$ & + & $(-)$-cis- $\left(3^{\prime} R, 4^{\prime} R\right)-4^{\prime}$-angeloylkhellactone \\
\hline 11 & $367[\mathrm{M}+\mathrm{Na}]^{+} ; 383[\mathrm{M}+\mathrm{K}]^{+}$ & 344 & $327,245,227$ & $+11^{\circ}$ & N.A. & $(+)$-trans- $\left(3^{\prime} S, 4^{\prime} R\right)-3^{\prime}$-angeloylkhellactone \\
\hline
\end{tabular}

N.A.: not applicable. 
Table 2. ${ }^{1} \mathrm{H}-\mathrm{NMR}$ spectroscopic data of angular-type pyranocoumarin compounds 1-11 in $\mathrm{CDCl}_{3}(600 \mathrm{M})$.

\begin{tabular}{|c|c|c|c|c|c|c|c|c|c|c|c|}
\hline \multirow{2}{*}{ Position } & \multicolumn{11}{|c|}{ Compound } \\
\hline & 1 & 2 & 3 & 4 & 5 & 6 & 7 & 8 & 9 & 10 & 11 \\
\hline 3 & $6.27(\mathrm{~d}, 9.5)$ & $6.26(\mathrm{~d}, 9.5)$ & $6.23(\mathrm{~d}, 9.5)$ & $6.25(\mathrm{~d}, 9.6)$ & $6.24(\mathrm{~d}, 9.6)$ & $6.25(\mathrm{~d}, 9.6)$ & $6.23(\mathrm{~d}, 9.5)$ & $6.24(\mathrm{~d}, 9.5)$ & $6.27(\mathrm{~d}, 9.6)$ & $6.24(\mathrm{~d}, 9.5)$ & $6.27(\mathrm{~d}, 9.5)$ \\
\hline 4 & $7.67(\mathrm{~d}, 9.5)$ & $7.61(\mathrm{~d}, 9.5)$ & $7.60(\mathrm{~d}, 9.5)$ & $7.60(\mathrm{~d}, 9.6)$ & $7.60(\mathrm{~d}, 9.6)$ & $7.61(\mathrm{~d}, 9.6)$ & $7.59(\mathrm{~d}, 9.5)$ & $7.60(\mathrm{~d}, 9.5)$ & $7.65(\mathrm{~d}, 9.6)$ & $7.61(\mathrm{~d}, 9.5)$ & $7.67(\mathrm{~d}, 9.5)$ \\
\hline 7 & $6.81(\mathrm{~d}, 8.7)$ & $6.82(\mathrm{~d}, 8.6)$ & $6.82(\mathrm{~d}, 8.6)$ & $6.81(\mathrm{~d}, 8.6)$ & $6.82(\mathrm{~d}, 8.6)$ & $6.81(\mathrm{~d}, 8.6)$ & $6.81(\mathrm{~d}, 8.6)$ & $6.81(\mathrm{~d}, 8.6)$ & $6.81(\mathrm{~d}, 8.5)$ & $6.82(\mathrm{~d}, 8.7)$ & $6.83(\mathrm{~d}, 8.6)$ \\
\hline $3^{\prime}$ & $3.89(\mathrm{~d}, 5.0)$ & $5.37(\mathrm{~d}, 5.0)$ & $5.46(\mathrm{~d}, 5.0)$ & $5.41(\mathrm{~d}, 4.8)$ & $5.37(\mathrm{~d}, 4.8)$ & $5.34(\mathrm{~d}, 5.0)$ & $5.42(\mathrm{~d}, 4.8)$ & $5.34(\mathrm{~d}, 4.8)$ & $5.49(\mathrm{~d}, 4.8)$ & $4.10(\mathrm{~d}, 4.8)$ & $5.28(\mathrm{~d}, 3.6)$ \\
\hline $4^{\prime}$ & $5.23(\mathrm{~d}, 5.0)$ & $6.65(\mathrm{~d}, 5.0)$ & $6.72(\mathrm{~d}, 5.0)$ & $6.63(\mathrm{~d}, 4.8)$ & $6.65(\mathrm{~d}, 4.8)$ & $6.57(\mathrm{~d}, 5.0)$ & $6.67(\mathrm{~d}, 4.8)$ & $6.57(\mathrm{~d}, 4.8)$ & $5.25(\mathrm{~d}, 4.8)$ & $6.51(\mathrm{~d}, 4.8)$ & $5.09(\mathrm{~d}, 3.6)$ \\
\hline $6^{\prime}$ & $1.48(\mathrm{~s})$ & $1.49(\mathrm{~s})$ & $1.51(\mathrm{~s})$ & $1.49(\mathrm{~s})$ & $1.48(\mathrm{~s})$ & $1.46(\mathrm{~s})$ & $1.50(\mathrm{~s})$ & $1.47(\mathrm{~s})$ & $1.51(\mathrm{~s})$ & $1.50(\mathrm{~s})$ & $1.52(\mathrm{~s})$ \\
\hline $2^{\prime \prime}$ & - & - & - & - & - & $\begin{array}{l}2.26(\mathrm{~m}) \\
2.25(\mathrm{~m})\end{array}$ & - & $\begin{array}{l}2.30(\mathrm{~m}) \\
2.20(\mathrm{~m})\end{array}$ & - & - & - \\
\hline $3^{\prime \prime}$ & - & $6.14(\mathrm{q}, 7.2)$ & $6.13(\mathrm{q}, 7.2)$ & $6.13(\mathrm{q}, 7.2)$ & $2.11(\mathrm{~s})$ & $2.10(\mathrm{~m})$ & $6.13(\mathrm{q}, 7.2)$ & $2.15(\mathrm{~m})$ & $6.18(\mathrm{q}, 7.2)$ & - & $6.11(\mathrm{q}, 7.2)$ \\
\hline $4^{\prime \prime}$ & - & $1.97(\mathrm{~d}, 7.2)$ & $2.00(\mathrm{~d}, 7.2)$ & $1.98(\mathrm{~d}, 7.2)$ & - & $0.98(\mathrm{~d}, 7.2)$ & $1.98(\mathrm{~d}, 7.2)$ & $0.98(\mathrm{~d}, 7.2)$ & $2.00(\mathrm{~d}, 7.2)$ & - & $1.92(\mathrm{~d}, 7.2)$ \\
\hline $5^{\prime \prime}$ & - & $1.88(\mathrm{~s})$ & $1.87(\mathrm{~s})$ & $1.89(\mathrm{~s})$ & - & $0.98(\mathrm{~d}, 7.2)$ & $1.86(\mathrm{~s})$ & $0.98(\mathrm{~d}, 7.2)$ & $1.91(\mathrm{~s})$ & - & $1.85(\mathrm{~s})$ \\
\hline $5^{\prime \prime \prime}$ & - & - & $1.85(\mathrm{~s})$ & $0.97(\mathrm{~d}, 7.2)$ & $1.88(\mathrm{~s})$ & - & $2.20(\mathrm{~s})$ & $0.98, \mathrm{~d}, 7.2$ & - & $1.91, \mathrm{~s}$ & - \\
\hline Ref. & [6] & [6] & {$[6]$} & [8] & [23] & {$[24,25]$} & {$[26]$} & {$[26,27]$} & [14] & [14] & [20] \\
\hline
\end{tabular}


Figure 2. Typical HPLC-UV (323 nm) chromatograms of compounds $\mathbf{1}$ (A) and $\mathbf{3}$ (B) on a CHIRALPAK AD-RH semi-preparative column.

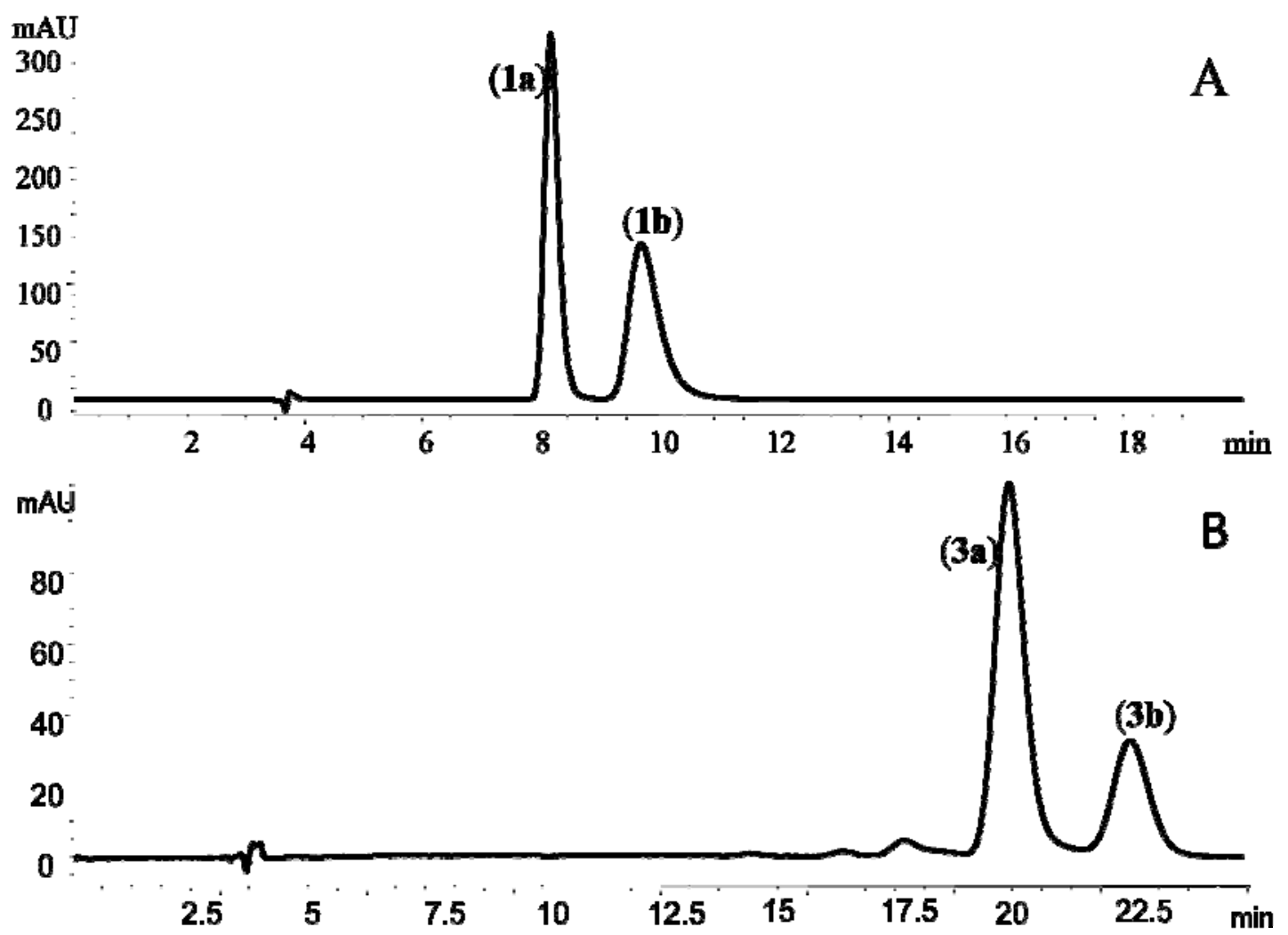

To confirm this speculation, (+)-praeruptorin $\mathrm{A}\left[[\alpha]_{\mathrm{D}}^{20}+59^{\circ}(c, 1.0), \mathbf{2 a}\right],(-)$-praeruptorin $\mathrm{A}$ $\left[[\alpha]_{\mathrm{D}}^{20}-61^{\circ}(c, 1.0), \mathbf{2 b}\right],(+)$-praeruptorin $\mathrm{E}(\mathbf{4})$, and the two metabolites of $\mathbf{2 b}$ formed in rat plasma, $(-)$-cis- $\left(3^{\prime} R, 4^{\prime} R\right)-3^{\prime}$-angeloyl khellactone $\left[[\alpha]_{\mathrm{D}}^{20}-57^{\circ}(c, 1.0), 9\right]$ and $(-)$-cis- $\left(3^{\prime} R, 4^{\prime} R\right)-4^{\prime}$-angeloylkhellactone $\left[[\alpha]_{\mathrm{D}}^{20}-39^{\circ}(c, 1.0), \mathbf{1 0}\right]$, were incubated with rat liver microsomes. The chemical structures and absolute configurations of $\mathbf{2 a}, \mathbf{2 b}, \mathbf{9}$ and $\mathbf{1 0}$ have been unambiguously identified using NMR analysis and optical rotation data in our laboratory [14], while 4 was commercially available and its chemical structure was double checked by comparing its mass spectral profile and optical rotation data $\left[[\alpha]_{\mathrm{D}}^{20}+35^{\circ}(c, 1.0)\right]$ with the literature report [8].

When incubated with rat liver microsomes (RLMs) in presence of the NADPH-regenerating system, all these five pyranocoumarins generated cis-khellactone which was eluted at 12.0 min under present achiral HPLC conditions and exhibited identical UV and MS spectra to those of the authentic $( \pm$ )-cis-khellactone (Figure 3). When the cis-khellactone produced from each reaction was collected and analyzed using chiral LC-MS/MS, the products formed from (+)-praeruptorin E (4) and $(+)$-praeruptorin A (2a) exhibited the same retention time at $9.0 \mathrm{~min}$ as that of $(-)$-cis-khellactone (1b, Figure 4A), while those metabolites of (-)-praeruptorin A (2b), (-)-(3'R, $\left.4^{\prime} R\right)-3^{\prime}-$ angeloylkhellactone $(9)$ and $(-)-\left(3^{\prime} R, 4^{\prime} R\right)-4^{\prime}$-angeloylkhellactone (10) shared the same retention time (10.6 min) with (+)-cis-khellactone (1a, Figure 4B).

These results together with the optical rotation data of these parent pyranocoumarins (Table 1) support that their respective hydrolytic metabolite cis-khellactone keeps the absolute configurations during hydrolysis of the parent compounds in rat liver microsomal proteins. 
Figure 3. Typical achiral HPLC-UV $(323 \mathrm{~nm})$ chromatograms of incubations of compounds 2-10 in rat liver microsomes in the presence of a NADPH-regenerating system.

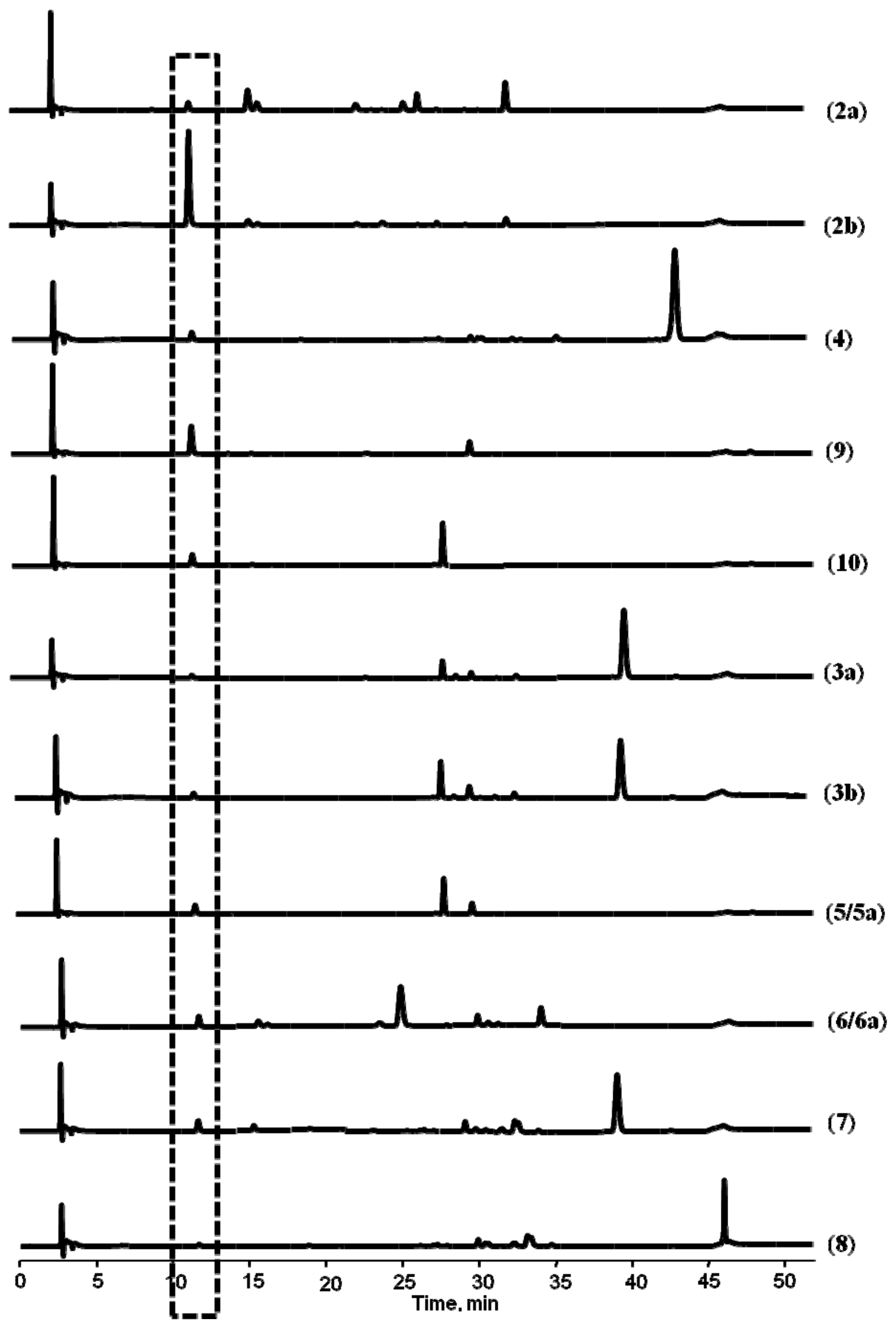


Figure 4. Typical extracted ion current chromatograms (XIC) $(263.1>203.1)$ of authentic $1 \mathrm{a}(\mathrm{A})$ and $\mathbf{1 b}(\mathrm{B})$, and samples from incubations of compound 5 (C) and 6 (D) with rat liver microsomes under chiral LC-MS/MS analytical conditions.
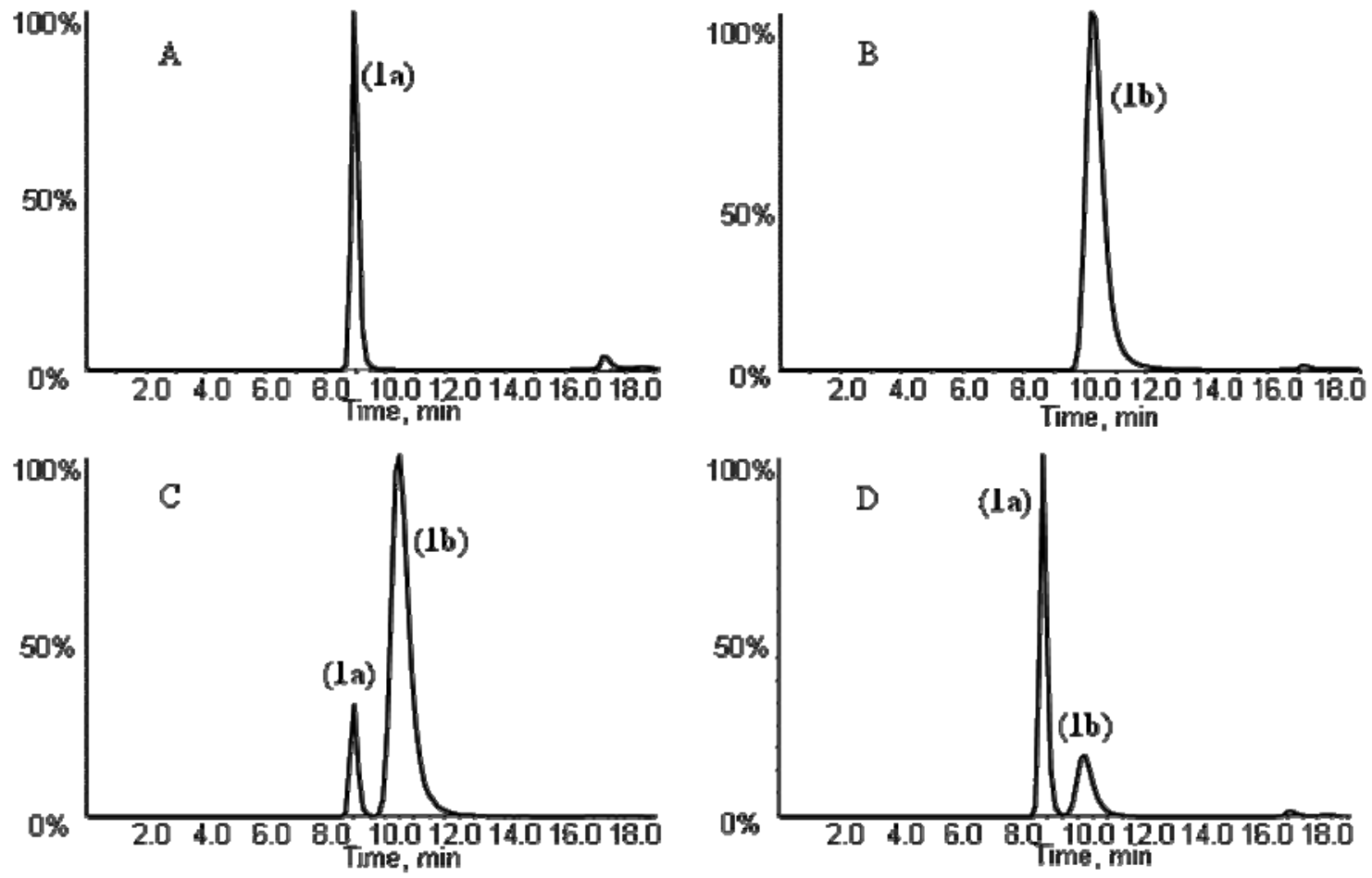

In contrast, when 2a [(+)-cis-(3'S,4'S)-3'-angeloyl-4'-acetylkhellactone] was subjected to basic

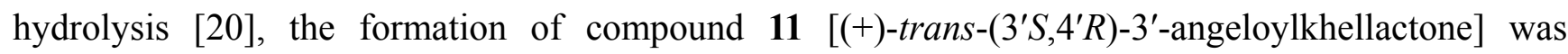
evidenced by NMR and LC-MS/MS analysis and its optical rotation (Tables 1 and 2). Peucedanocoumarins I, II and III, which are also trans-khellactone type coumarins, yielded cis-khellactone after alkaline hydrolysis [23]. Thus, epimerization might occur during alkaline treatment of pyranocoumarins and finally may cause misidentification of the absolute configurations of parent compounds.

This method was further applied to the determination of the absolute configuration of another four pyranocoumarin compounds 5a, 6a, 7 and $\mathbf{8}$ isolated from Qian-hu. cis-Khellactone obtained from the enzymatic hydrolysis of compound $\mathbf{5 a}$ was eluted at $12.0 \mathrm{~min}$ on the achiral column (Figure 3) and only appeared at $10.6 \mathrm{~min}$ on the chiral LC-MS/MS (Figure 4B), and identified as (+)-cis-khellactone by comparison with the reference compound. Thus a $\left(3^{\prime} R, 4^{\prime} R\right)$ configuration of compound $\mathbf{5 a}$ was suggested. Furthermore, the optical rotation of $\mathbf{5 a}$ in chloroform was $[\alpha]_{\mathrm{D}}^{20}+3.5^{\circ}(c, 1.0)$ and the NMR data supported the structure as cis-3'-acetyl-4'-angeloylkhellactone (Table 2). These findings demonstrated that the absolute configuration of 5a predicted from the absolute configuration of its metabolite cis-khellactone corresponded well with the structure identified based on LC-MS/MS, NMR and polarimetric analysis (Tables 1 and 2). These data of 5a were in good agreement with those of pteryxin [( $\left.3^{\prime} R, 4^{\prime} R\right)-3^{\prime}$-acetyl-4'-angeloylkhellactone], which has been isolated from $P$. praeruptorum [23], thus, compound 5a was unambiguously identified as pteryxin $\left[(+)\right.$-cis- $\left(3^{\prime} R, 4^{\prime} R\right)-3^{\prime}$-acetyl-4'-angeloylkhellactone]. 
Similarly, the end products obtained from hydrolysis of compounds 6a, 7, 8 by RLMs (Figure 3) showed the same retention time as that of (-)-cis-khellactone on the chiral LC-MS/MS system (Figure $4 \mathrm{~A})$, supporting the existence of $c i s-\left(3^{\prime} S, 4^{\prime} S\right)$ configurations in these compounds. Correspondingly, the NMR data (Table 2) of compound 6a supported it as cis-3'-isovaleryl-4'-acetyl khellactone and polarimetric measurement revealed a positive optical rotation $\left[[\alpha]_{\mathrm{D}}^{20}+33^{\circ}(c, 1.0)\right]$. Compound $6 \mathbf{a}$ was thereby identified as $(+)$-cis- $\left(3^{\prime} S, 4^{\prime} S\right)$-3'-isovaleryl-4'-acetylkhellactone. NMR analysis (Table 2) of compounds 7 and 8 identified their structures as cis-3'-angeloyl-4'-senecioylkhellactone and cis-3',4'diisovalerylkhellactone, respectively. Their optical rotations were $+31^{\circ}(c, 1.0)$ and $+35^{\circ}(c, 1.0)$. Taken together, the structures were assigned as (+)-cis-(3'S,4'S)-3'-angeloyl-4'-senecioylkhellactone (7) and (+)-cis-(3'S, 4'S)-3',4'-diisovalerylkhellactone (8). So far, $( \pm)$-dihydrosamidin, the racemic form of compound 6a, has been isolated from P. Turgeniifolium [24,25], while neither the racemate nor any of the single enantiomers has been reported for Qian-hu. Both 3'-angeloyl-4'-senecioylkhellactone and 3',4'-diisovalerylkhellactone have been reported in P. japonicum, but not in P. praeruptorum (Qian-hu) [26] and their absolute configurations were not determined in the previous report [27]. Again, determination of the absolute configurations of pyranocoumarin compounds 5a, 6a, 7 and 8 based on chiral LC-MS/MS analysis of their respective hydrolytic metabolite cis-khellactone formed by RLMs were proved to be feasible and should be applicable to other pyranocoumarins that have a hidden C-3' and/or C-4' hydroxy functionality that can be released by enzymatic transformations.

It's interesting to note that compounds $\mathbf{5}$ and $\mathbf{6}$, which were obtained from Qian-hu to prepare 5a and 6a through crystallization, exhibited similar positive optical rotation and identical NMR data as compounds 5a and 6a, respectively. However, when subjected to enzymatic hydrolysis, both compounds formed the two optical isomers of cis-khellactone (Figure 4C,D), indicating that compounds 5 and $\mathbf{6}$ were isolated from Qian-hu as enantiomerically enriched compounds. This was further confirmed by two peaks observed in chromatograms obtained from enantioseperation of compounds 5 and $\mathbf{6}$ (data not shown) and the enantiometric ratios $( \pm$ ) of cis-khellactone formed from 5 $(7 / 1)$ and $6(1 / 8)$ by RLMs (Table 1). Thus, the NMR data plus net optical rotation could not distinguish the enantiomerically enriched angular-type pyranocoumarin from its pure enantiomer.

In the present study, $( \pm)$-praeruptorin B (3) was enantioseparated, for the first time, to obtain the two enantiomers. The two optical isomers (3a and $\mathbf{3 b}$ ) were also subjected to enzymatic hydrolysis followed by chiral LC-MS/MS analysis individually. Similar to those observed with the two isomers from ( \pm )-praeruptorin A (2), cis-khellactone from (+)-praeruptorin B (3a) shared the same retention time (9.0 min) with (-)-cis-khellactone (Figure 4A), while cis-khellactone from (-)-praeruptorin B (3b) was observed at $10.6 \mathrm{~min}$, the same as $(+)$-cis-khellactone (Figure 4B), suggesting that the metabolite cis-khellactone keep the absolute configuration as their respective parent optical isomer. Again, this result agreed well with that obtained from a combination of NMR and polarimetric analysis (Tables 1 and 2) in the present study and the previous report [7]. Thus, (+)-praeruptorin B (3a) was identified as

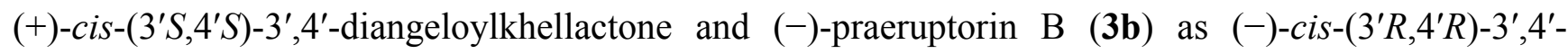
diangeloylkhellactone.

The stereoselectivity in pharmacological actions [13], metabolism [14] and absorption [28] of praeruptorin A have been revealed by previous studies, indicating that it is of great importance to determine the absolute configurations of the angular-type pyranocoumarins when correlate their structures with the resultant biological interactions during pharmacological/toxicological evaluation 
and/or ADME screening. Furthermore, because most pyranocoumarins from Qian-hu naturally exist as enantiomers and/or diastereoisomers, misidentification of the identity of the compound studied has occurred [29-31]. Thus, it is crucial to establish a method which enables rapid determination of the absolute configurations of the pyranocoumarin compounds to be worked on. These findings obtained in the present study demonstrated that it is feasible to determine the absolute configurations of pyranocoumarins from that of the hydrolytic product khellactone using enzymatic hydrolysis coupled with chiral LC-MS/MS analysis. Because of the high sensitivity and selectivity afforded by LC-MS/MS techniques, this method can be used to determine the configuration of compounds of this chemical type with advantages in lower quantity of the tested compounds required for in vitro incubation.

\section{Experimental}

\subsection{Materials}

Qian-hu was obtained from Ningguo, Anhui Province, China and the crude drug was authenticated as the dried roots of $P$. praeruptorum DUNN by Professor Pengfei Tu from Department of Natural Medicines, Peking University (Beijing, China). The specimens were stored at the State Key Laboratory of Quality Research in Chinese Medicine, University of Macau.

The crude drug $(6 \mathrm{~kg})$ was crushed into a powder and extracted with $95 \%$ ethanol $\left(50 \mathrm{~L} \times 3,80{ }^{\circ} \mathrm{C}\right)$ to afford an extract $(1.83 \mathrm{~kg})$. An aliquot of the extract $(50 \mathrm{~g})$ was loaded onto a silica gel column (200-300 mesh, $800 \mathrm{~g})$ and fractionated with petroleum ether-ethyl acetate $(20: 1 \rightarrow 1: 2, v / v)$ to get 11 fractions (Fractions 1-11). Fraction 4 (4.2 g) was loaded onto another silica gel column (200-300 mesh, $100 \mathrm{~g})$ was and compound $2(432 \mathrm{mg})$ was eluted with petroleum ether-ethyl acetate $(8: 1 \rightarrow 1: 1, v / v)$. Compounds $3(195 \mathrm{mg})$ and $4(52 \mathrm{mg})$ were obtained by recrystallization of Fraction $5(5.3 \mathrm{~g})$ and Fraction $8(7.1 \mathrm{~g})$ from $\mathrm{MeOH}$, respectively. Compound $6(12 \mathrm{mg})$ was isolated from the remaining solution of Fraction 5 using a semi-preparative COSMOSIL 5C18-AR-II column $(250 \mathrm{~mm} \times 10.0 \mathrm{~mm}$ i.d., particle size $5 \mu \mathrm{m}$, Nacalai Tesque, Kyoto, Japan) that eluted with $\mathrm{MeOH}-\mathrm{H}_{2} \mathrm{O}(65: 35, v / v)$ at a flow rate of $2.5 \mathrm{~mL} / \mathrm{min}$. The remaining solution of Fraction 8 was introduced to the same semi-preparative HPLC system and eluted with $\mathrm{MeOH}-\mathrm{H}_{2} \mathrm{O}(69: 31, v / v)$ to afford 7 (11 mg) and 8 (17 mg). Compound 5 (13 mg) was prepared from Fraction 3 by semi-preparative HPLC with an isocratic elution utilizing $\mathrm{MeOH}-\mathrm{H}_{2} \mathrm{O}(77: 23, v / v)$. Compounds 5a $\left[(+)-c i s-\left(3^{\prime} R, 4^{\prime} R\right)-3^{\prime}\right.$-acetyl-4'-angeloylkhellactone] and 6a [(+)-cis-(3'S,4'S)-3'-isovaleryl-4'-acetylkhellactone] were obtained as white needles by recrystallization of 5 and $\mathbf{6}$ from methanol.

A basic hydrolysis of $2(70 \mathrm{mg})$ was carried out to obtain $1(23 \mathrm{mg})$ following a procedure described previously by our group [14]. (+)-Praeruptorin A [(+)-cis-(3'S,4'S)-3'-angeloyl-4'-acetylkhellactone, 2a] and (-)-praeruptorin A [(-)-cis- $\left(3^{\prime} R, 4^{\prime} R\right)-3^{\prime}$-angeloyl-4'-acetylkhellactone, $\left.2 \mathbf{b}\right]$ were obtained by enantioseperation of compound 2 according to our previous report [14]. (-)-cis-( $\left.3^{\prime} R, 4^{\prime} R\right)$ $3^{\prime}$-angeloylkhellactone (9) and (-)-cis-(3'R,4'R)-4'-angeloylkhellactone (10) were prepared from an incubation of compound $\mathbf{2 b}$ with rat plasma and unambiguously identified using NMR and LC-MS/MS analysis [14]. Compound $\mathbf{1 1}$ was obtained from basic hydrolysis of compound 2a, according to a method reported by $\mathrm{Wu}$ and co-workers [20]. Additionally, authentic compounds 2, 2a and 4 were purchased from Shanghai Traditional Chinese Medicine Research Center (Shanghai, China) and their 
identities were confirmed using LC-MS/MS and polarimetric analysis. The purity of all the compounds was all above $98 \%$ as determined by achiral HPLC-UV. The identities of all pyranocoumarin constituents 1-11 isolated from Qian-hu were identified using polarimetric analsyis, LC-UV-MS/MS and NMR analysis and confirmed by comparison with previous reports. The spectrometric and spectroscopic data were summarized in Tables 1 and 2.

Pooled rat liver microsomes (RLMs) were prepared at the School of Biomedical Sciences, the Chinese University of Hong Kong by differential centrifugation according to a standard procedure reported previously [32]. The content of microsomal proteins was determined using Lowry's method [33] and stored at $-80{ }^{\circ} \mathrm{C}$ until use.

Glucose 6-phosphate (G-6-P), glucose-6-phosphate dehydrogenase (G-6-PD), and $\beta$-nicotinamide adenine dinucleotide phosphate $\left(\beta\right.$-NADP $\left.{ }^{+}\right)$were obtained from Sigma-Aldrich Corp. (St. Louis, MO, USA). Formic acid, acetonitrile and methanol of HPLC grade were purchased from Merck (Darmstadt. Germany). Ultra-pure water was obtained in house using a Milli-Q plus water purification system (Millipore, Bedford, MA, USA).

\subsection{Enantioseparation of Angular-type Pyranocoumarins from Qian-hu}

Enantioseparation of the enantiometric mixtures ( \pm )-cis-khellactone (1) and ( \pm )-praeruptorin B (3) were carried out on a semi-preparative CHIRALPAK AD-RH column $(10 \times 250 \mathrm{~mm}$ I.D., particle size $5 \mu \mathrm{m}$, Daicel, Tokyo, Japan). The mobile phases were acetonitrile- $\mathrm{H}_{2} \mathrm{O}$ with a volumetric ratio of $30 / 70$ for 1 and $45 / 55$ for 3 . The flow rates were $2.5 \mathrm{~mL} / \mathrm{min}$ for elution of both analytes. Each analyte eluted was collected separately and the solvent was removed under reduced pressure to yield $1 \mathrm{a}(9.5 \mathrm{mg})$ and $\mathbf{1 b}(8.5 \mathrm{mg}), \mathbf{3 a}(23.6 \mathrm{mg})$ and $\mathbf{3 b}(19.9 \mathrm{mg})$. The purity of all the enantiomers was more than $98 \%$ as determined using chiral LC-UV/MS/MS.

\subsection{Polarimetric and NMR Analysis}

The polarimetric analysis was performed on a Perkin-Elmer 243B digital polarimeter (PerkinElmer, Netherlands) in chloroform at $589.3 \mathrm{~nm}, 20{ }^{\circ} \mathrm{C}$. Compounds 1-11 were dissolved in $\mathrm{CDCl}_{3}$ containing $0.3 \%$ trimethylsilane (TMS) and their ${ }^{1} \mathrm{H}$ NMR spectra were acquired on a Bruker Avance 600 spectrometer (600 MHz, Bruker GmbH, Bremen, Germany). Chemical shifts were reported in $\delta$ scale in units of part per million (ppm) with TMS as the reference, and coupling constants $(J)$ were expressed in units of Hertz $(\mathrm{Hz})$.

\subsection{Hydrolysis of Angular-type Pyranocoumarins from Qian-hu by Rat Liver Microsomes}

Enzymatic hydrolysis of each of the angular-type pyranocoumarins (final concentration $25 \mu \mathrm{M}$ ) was carried out in a $200 \mu \mathrm{L}$ reaction system containing $1 \mathrm{mg} / \mathrm{mL}$ of rat liver microsomal proteins in $0.1 \mathrm{M}$ potassium phosphate buffer $\left(\mathrm{pH} \mathrm{7.4)}\right.$ at $37{ }^{\circ} \mathrm{C}$. The reactions were initiated by adding the NADPH-regenerating system ( $4 \mathrm{mM} \mathrm{MgCl}_{2}, 1 \mathrm{mM} \beta$-NADP ${ }^{+}, 1 \mathrm{mM} \mathrm{G-6-P}$ and $1 \mathrm{U} / \mathrm{mL}$ of G-6-PD). Reactions were stopped at $60 \mathrm{~min}$ by adding an equal volume of ice-cold methanol and the samples centrifuged to remove the proteins before subjected to achiral HPLC-UV analysis. 


\subsection{Achiral HPLC-UV Analysis}

The achiral HPLC-UV analysis was performed on an Agilent 1200 series liquid chromatographic system (Agilent Technologies, Palo Alto, CA, USA) that equipped with a vacuum degasser, a quaternary pump, an autosampler and a diode array detector (DAD) system. Data acquisition was controlled by an Agilent ChemStation B 3.0 software. Sample separation was performed on an ODS reversed-phase $\mathrm{C}_{18}$ column ( $250 \mathrm{~mm} \times 4.6 \mathrm{~mm}$ I.D., particle size $5 \mu \mathrm{m}$, Agilent) at $35^{\circ} \mathrm{C}$. The mobile phase consisted of water containing $0.1 \%$ formic acid (A) and methanol (B). A gradient elution was carried out at $1.0 \mathrm{~mL} / \mathrm{min}$ as follows: 0-4 min, 25-50\% B; 4-16 min, 50-53\% B; 16-17 min, 53-56\% B; 17-20 min, 56\% B; 20-23 min, 56-69\% B; 23-40 min, 69-76\% B; 40-41 min, 76-100\% B; 41-52 min, $100 \%$ B. All reference compounds and samples from reactions were monitored at $323 \mathrm{~nm}$ and UV spectra were recorded over $200-400 \mathrm{~nm}$. The injection volume was $70 \mu \mathrm{L}$. cis-Khellactone, the end product yielded from the aforementioned reactions of all pyranocoumarins, was eluted at the retention time of $12.0 \mathrm{~min}$ under the present analytical conditions and collected separately for further chiral LC-MS/MS analysis.

\subsection{Chiral HPLC-MS/MS Analysis}

Chiral LC-MS/MS analysis was performed on an Agilent 1200SL series (Agilent) liquid chromatography coupled online with an API 4000 Q-trap ${ }^{\circledR}$ mass spectrometer (Applied Biosystems, Foster City, CA, USA). The LC system consisted of a vacuum degasser, a binary pump, and an autosampler. Chromatographic separation was performed on an analytical CHIRALPAK AD-RH column $(5 \times 150 \mathrm{~mm}$ I.D., particle size $5 \mu \mathrm{m}$, Daicel, Tokyo, Japan $)$, which was eluted with acetonitrile- $\mathrm{H}_{2} \mathrm{O}(30: 70, \mathrm{v} / \mathrm{v})$ at a flow rate of $0.65 \mathrm{~mL} / \mathrm{min}$. The mass spectrometer was equipped with a Turbo $\mathrm{V}^{\mathrm{TM}}$ source and a Turbo Ion Spray probe $\left(500{ }^{\circ} \mathrm{C}\right)$ and operated in positive ion multiple reactions monitoring (MRM) mode. Ion optics was tuned using polypropylene glycol (PPG) standard dilution solvents. Nitrogen was used as the nebulizer, heater, curtain and collision gases. Optimum ion source parameters for cis-khellactone were as follows: nebulizer (GS1), heater (GS2) and curtain gas flow rates 50, 50, 10 instrument units, respectively; ionspray voltage $4500 \mathrm{~V}$; heater gas temperature $550{ }^{\circ} \mathrm{C}$; declustering potential (DP) $100 \mathrm{~V}$. The ion pairs used for monitoring cis-khellactone were $263.1>245.1$ and 263.1 > 203.1. Collision energies (CE) were set as $25 \mathrm{eV}$ and $30 \mathrm{eV}$ for the two ion pairs, respectively. The Applied Biosystems Analyst Software package (Version 1.5) was used for instrument control, data acquisition and processing.

\section{Conclusions}

In the present study, a new method using enzymatic hydrolysis coupled with chiral LC-MS/MS analysis was developed to assist the determination of the absolute configuration of angular-type pyranocoumarins. It has been proved to be rapid and sensitive and demonstrated success in identification of this chemical type from Qian-hu. 


\section{Acknowledgments}

The research was supported by the National Basic Research Program of China 973 program (Grant No.2009CB522707) and the Research Committee of University of Macau (reference No.UL016/09-Y4/CMS/WYT01/ICMS, MYRG 208 (Y2-L4)-ICMS11-WYT).

\section{References and Notes}

1. The State Pharmacopoeia Commission of P.R. China. Radix Peucedani. In Pharmacopoeia of the People's Republic of China Beijing; Chemical Industry Press: Beijing, China; 2010; Volume I, p. 248.

2. Chang, H.M.; But, P.P.H.; Yao, S.C.; Wang, L.L.; Yeung, S.C.S. Pharmacology and Applications of Chinese Materia Medica; World Scientific Publisher: Singapore, 2001; Volume 2, p. 905.

3. Zhao, N.C.; Jin, W.B.; Zhang, X.H.; Guan, F.L.; Sun, Y.B.; Adachi, H.; Okuyama, T. Relaxant effects of pyranocoumarin compounds isolated from a Chinese medical plant, Bai-Hua Qian-Hu, on isolated rabbit tracheas and pulmonary arteries. Biol. Pharm. Bull. 1999, 22, 984-987.

4. Chang, T.H.; Adachi, H.; Okuyama, T.; Zhang, K.Y. Effects of 3'-angeloyloxy-4'-acetoxy-3',4'dihydroseselin on myocardial dysfunction after a brief ischemia in anesthetized dogs. Acta Pharmacol. Sin. 1994, 15, 388-391.

5. Fong, W.F.; Zhang J.X.; Wu, J.Y.; Tse, K.W.; Wang, C.; Cheung, H.Y.; Yang, M.S. Pyranocoumarin(+/-)-4'-O-acetyl-3'-O-angeloyl-cis-khellactone induces mitochondrial-dependent apoptosis in HL-60 cells. Planta Med. 2004, 70, 489-495.

6. Chen, Z.X.; Huang, B.S.; She, Q.L.; Zeng, G.F. The chemical constituents of Bai-hua-qian-hu, the root of Peucedanum praeruptorum Dunn. (umbelliferae) - four new coumarins. Yao Xue Xue Bao 1979, 14, 486-496.

7. Okuyama, T.; Shibata, S. Studies on coumarins of a Chinese drug "Qian-Hu”. Planta Med. 1981, 42, 89-96.

8. Ye, J.S.; Zhang, H.Q.; Yuan, C.Q. Isolation and identification of coumarin praeruptorin E from the root of the Chinese drug Peucedanum praeruptorum DUNN (umbelliferae). Yao Xue Xue Bao 1982, 17, 431-434.

9. Tao, Y.; Luo, J.; Lu, Y.; Xu, D.; Hou, Z.; Kong, L.Y. Rapid identification of two species of Peucedanum by high-performance liquid chromatography-diode array detection-electrospray ionization tandem mass spectrometry. Nat. Prod. Commun. 2009, 4, 1079-1084.

10. Liang, T.G.; Yue, W.Y.; Li, Q.S. Chemopreventive effects of Peucedanum praeruptorum Dunn and its major constituents on SGC7901 gastric cancer cells. Molecules 2010, 15, 8060-8071.

11. Shen, X.L.; Chen, G.Y.; Zhu, G.Y.; Fong, W.F. ( \pm )-3'-O, 4'-O-dicynnamoyl-cis-khellactone, a derivative of $( \pm)$-praeruptorin A, resverses P-glycoprotein mediated multidrug resistance in cancer cells. Bioorg. Med. Chem. 2006, 14, 7138-7145.

12. Mizuno, A.; Okada, Y.; Nishino, H.; Okuyama, T. Anti-cancer activity of coumarins from Peucedanum praeruptum on second stage cancer. J. Tradit. Med. 1994, 11, 220-224. 
13. Xu, Z.; Wang, X.B.; Dai, Y.; Kong, L.Y.; Wang, F.Y.; Xu, H.; Lu, D.; Song, J.; Hou, Z.G. $( \pm)$-Praeruptorin A enantiomers exert distinct relaxant effects on isolated aorta rings dependent on endothelium and nitric oxide synthesis. Chem. Biol. Interact. 2010, 186, 239-246.

14. Song, Y.L.; Jing, W.H.; Zhao, H.Y.; Yan, R.; Li, P.T.; Wang, Y.T. Stereoselective metabolism of $( \pm)$-praeruptorin A, a calcium channel blocker from Peucedani Radix, in pooled liver microsomes of rats and humans. Xenobiotica 2011, 42, 231-247.

15. Kong, L.Y.; Li, Y.; Min, Z.D.; Li, X.; Zhu, T.R. Coumarins from peucedanum praeruptorum. Phytochemistry 1996, 41, 1422-1426.

16. Lou, H.X.; Sun, L.R.; Yu, W.T.; Fan, P.H.; Cui, L. Gao, Y.H.; Ma, B.; Ren, D.M.; Ji, M. Absolute configuration determination of angular dihydrocoumarins from Peucedanum praeruptorum. J. Asian Nat. Prod. Res. 2004, 6, 177-184.

17. Nakanishi, K.; Berova, N.; Woody, R.W. Circular Dichroism: Principles and Applications, 1st ed.; Wiley-VCH: New York, NY, USA, 1994; p. 473.

18. Imai, T. Human carboxylesterase isozymes: Catalytic properties and rational drug design. Drug Metab. Pharmacokinet. 2006, 21, 173-185.

19. Satoh, T.; Hosokawa, M. Structure, function and regulation of carboxylesterases. Chem. Biol. Interact. 2006, 162, 195-211.

20. Wu, X.L.; Kong, L.Y.; Min, Z.D. Studies on structure modification of (+)-praeruptorin A. Yao Xue Xue Bao 2002, 377, 527-534.

21. Song, Y.L.; Yan, R.; Jing, W.H.; Zhao, H.Y.; Wang, Y.T. Characterization of metabolism of $(+)$-praeruptorin $\mathrm{B}$ and $(+)$-praeruptorin $\mathrm{E}$ in human and rat liver microsomes by liquid chromatography coupled with ion trap mass spectrometry and time-of-flight mass spectrometry. Rapid Commun. Mass Spectrom. 2011, 25, 719-730.

22. Ruan, H.; Zhang, Z.; Liang, X.F.; Fu, Y.; Su, M.Q.; Liu, Q.L.; Wang, X.M.; Zhu, X. Metabolism of dl-praeruptorin a in rat liver microsomes using HPLC-electrospray ionization tandem mass spectrometry. Arch. Pharm. Res. 2011, 34, 1311-1321.

23. Takata, M.; Shibata, S.; Okuyama, T. Structures of angular pyranocoumarins of Bai-Hua Qian$\mathrm{Hu}$, the root of Peucedanum praeruptorum. Planta Med. 1990, 56, 307-311.

24. Rao, G.X.; Liu, Q.X.; Dai, W.S.; Sun, H.D. Chemical constituents of Peucedanum Turgeniifolium. Tianran Chanwu Yanjiu Yu Kaifa 1997, 9, 9-11.

25. Sun, H.D.; Lin, Z.W.; Niu, F.D.; Ding, J.K. A study of the Chinese drugs of Umbelliferae II. New coumarins of Peucedanum Turgeniifolium Wolff. Yunnan Zhiwu Yanjiu 1981, 3, 173-180.

26. Jong, T.T.; Hwang, H.C.; Jean, M.Y. An antiplatelet aggregation principle and X-ray structural analysis of cis-khellactone dister from Peucedanum japonicum. J. Nat. Prod. 1992, 55, 1396-1401.

27. Zhang, C.; Xiao, Y.Q.; Taniguchi, M.; Baba, K. Studies on chemical constituents in roots of Peucedanum praeruptorum. Zhongguo Zhongyao Zazhi 2005, 30, 675-677.

28. Jing, W.H.; Song, Y.L.; Yan, R.; Bi, H.C.; Li, P.T.; Wang, Y.T. Transport and metabolism of ( \pm )-praeruptorin A in Caco-2 cell monolayers. Xenobiotica 2011, 41, 71-81.

29. Huang, L.; Bi, H.C.; Liu, Y.H.; Wang, Y.T.; Xue, X.P.; Huang, M. CAR-mediated up-regulation of CYP3A4 expression in LS174T cells by Chinese herbal components. Drug Metab. Pharmacokinet. 2011, 26, 331-340. 
30. Yang, H.; Xu, L.N.; Sui, Y.J.; Liu, X.; He, C.Y.; Fang, R.Y.; Liu, J.; Hao, F.; Ma, T.H. Stimulation of airway and intenstinal mucosal secretion by natural coumarin CFTR activators. Front. Pharmacol. 2011, 2, 52.

31. Chen, G.H.; Tang, W.B.; Zhang, Z.F.; Cai, H.L.; Bai, L.Y. Activities and active components of Radix peucedani capable of inducing rice resistance to blast disease. Zhongguo Nongye Kexue 2010, 43, 1807-1814.

32. Lin, G.; Tang, J.; Liu, X.Q.; Jiang, Y.; Zheng, J. Deacetylclivorine: A gender-selective metabolite of clivorine formed in female Sprague-Dawley rat liver microsomes. Drug Metab. Dispos. 2007, $35,607-613$.

33. Lowry, O.H.; Rosenbrough, N.J.; Farr, A.L.; Randall, R.J. Protein measurement with the Folin phenol reagent. J. Biol. Chem. 1951, 193, 265-275.

Sample Availability: Samples of compounds 1-11 and enantiomers of compounds 1-3 are available from the authors.

(C) 2012 by the authors; licensee MDPI, Basel, Switzerland. This article is an open access article distributed under the terms and conditions of the Creative Commons Attribution license (http://creativecommons.org/licenses/by/3.0/). 